\title{
Opening Up To a Lot of Pain
}

\author{
Busejé Bailey
}

Putting myself on the line in this work has opened me up to a lot of pain, pain that I have buried deep, deep inside my soul. Pain that I've inherited from my parents through slavery and colonialism, and them through theirs. We've lost a homeland, our names and languages. Something we must not, can not talk about even five hundred years later. This issue has never been addressed, let alone redressed, in any major way. We never own, or are in charge of media or institutions of change. Therefore, we are unable to purge our race of this legacy. So we continue to pass the effects of shame and domination down from one generation to the next. Liberals continue to refer to our past and to us as descendants of slaves. Even very educated Africans in the diaspora refer to themselves as descendants of slaves, reinforcing the fabrication that we had no past before slavery. I am not saying that we should forget the plight of our ancestors, far from it ... It is a testament to the heroism of our tenacity for survival. But we are just one of many people who at one time or another were forced into slavery. Granted we were the largest on a global scale. This should not be a place of personal or race shame. Everyone wants to keep this in the closet, the listener(s) want me to stop lest they become defensive or hurt. But everyone wants to make me over, to make me acceptable, to teach me how to speak, how to dress, how to lighten my skin, to lose my African appearance. Well all this make over still doesn't work. I am still African.

In this body of work "Body Politic," I'm not interested in providing a universal solution to the problems entailed. What I am interested in is a personal visual representation as it relates to postmodern discourse on the issue of race, gender, location, space and mainstream art practices. In this work I explore what it is to be an African-Canadian-artist-woman and an advocate of feminist politics with a social and political responsibility to the world. I follow in the footsteps of those sisters and brothers who inform and inspire my practice. 


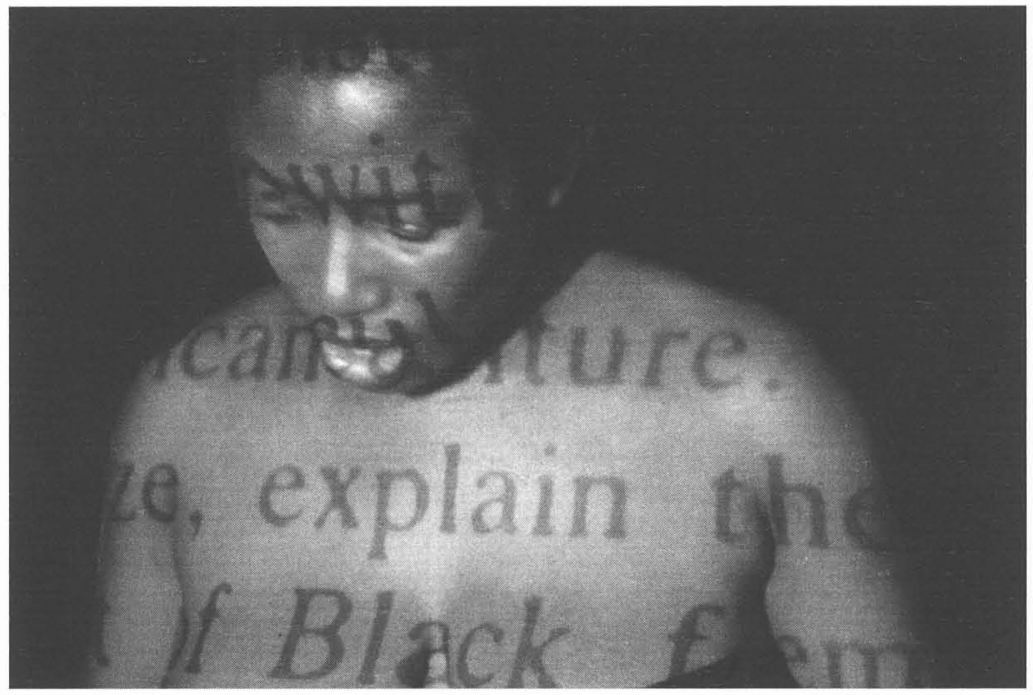




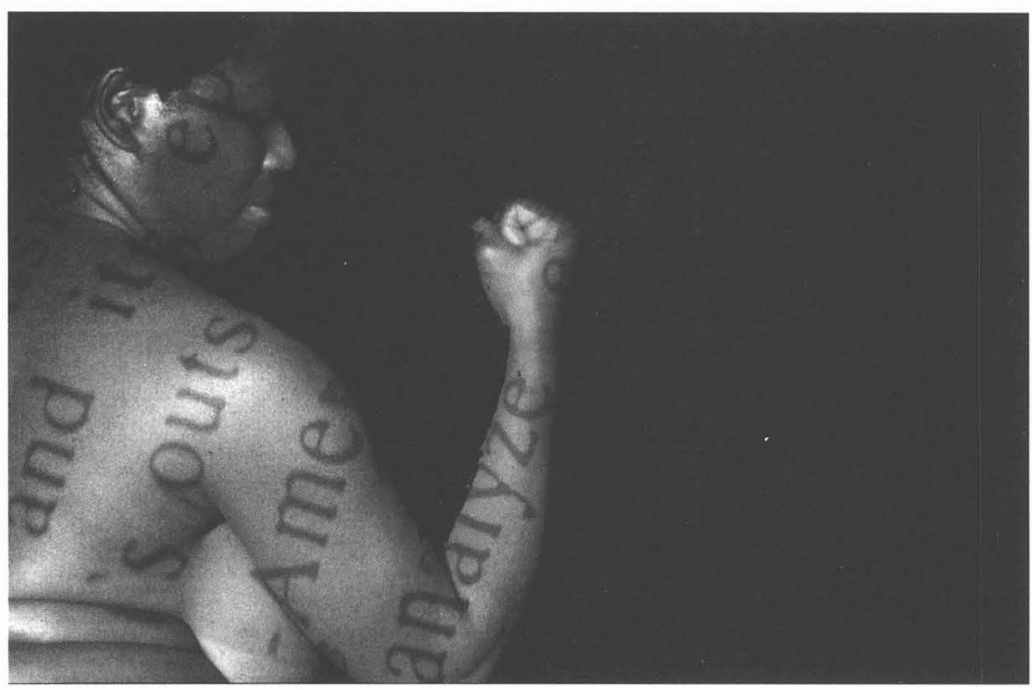




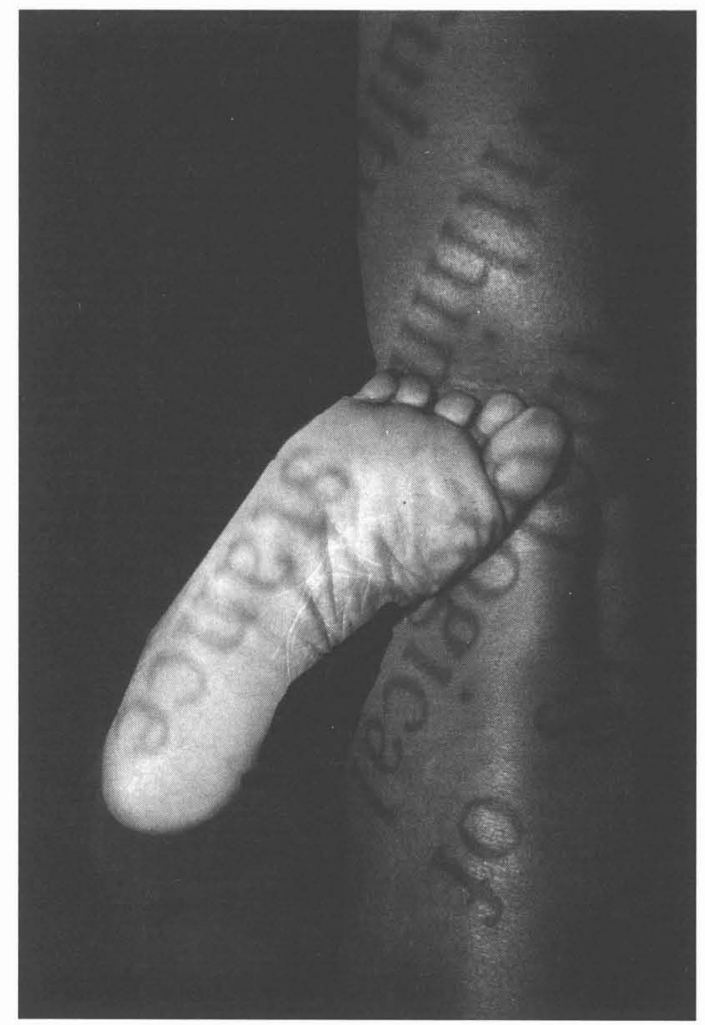




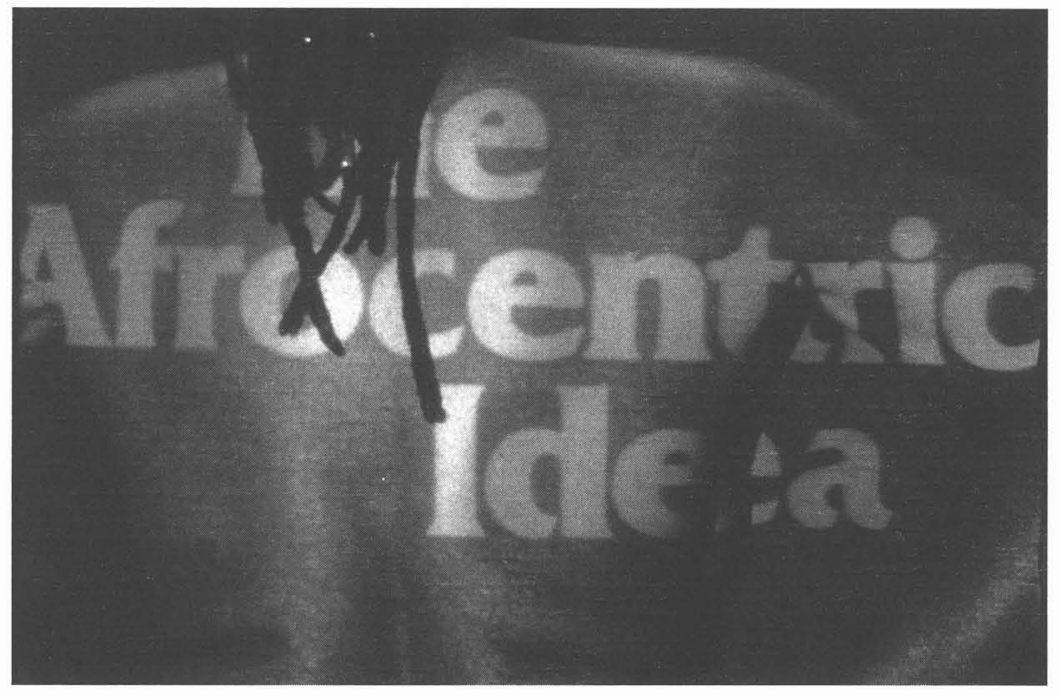

